\title{
Comparison for Chinese Subordinates as a Motivation Approach: Scale Development and Psychometric Properties
}

\author{
Jingjing Ge, Yezhuang Tian, Chengfeng Li \\ Harbin Institute of Technology (China) \\ gejingjing2020@gmail.com, tianyezhuang@,bit.edu.cn, lichengfeng@,brbeu.edu.cn
}

Received: January 2015

Accepted: August 2015

\section{Abstract:}

Purpose: Chinese people are motivated by social comparison and temporal comparison. Based on this finding, we conceptualized lateral comparison and vertical comparison as two distinct constructs that represent individual self-enhancement toward the nature of social comparison with others and temporal comparison with self over time. We hypothesized that as stable individual psychological difference, lateral comparison and vertical comparison would have differential effects on people's working behavior in the Chinese organizational context.

Design/methodology/approach: Based on a conceptualization approach to Chinese management research, we conducted two studies to develop and validate a two-factor comparison scale which includes three-item lateral comparison and a three-item vertical comparison.

Findings: Results from Study 1 provide evidence of convergent and discriminant validity of the scale, while Study 2 demonstrates the scale's predictive validity. Furthermore, in Study two, a field survey in multiple Chinese organizations showed that lateral comparison and vertical comparison had differential effects on employee task performance and organizational citizenship behavior.

Research limitations/implications: The theoretical and practical implications of this study are discussed in the working context in Chinese organizations and beyond. 
Originality/value: This finding integrates insights from previous research in social comparison and temporal comparison into a motivation approach that supervisors use toward subordinates in the Chinese organizational context.

Keywords: lateral comparison, vertical comparison, task performance, organizational citizenship behavior, scale development

\section{Introduction}

Comparison-a word is closely tied to self with others-is more prevalent than we normally think (Gilbert, Price \& Allan, 1995). Striving people to be more excellence is a core issue of motivation in management (Vroom, 1964). The persuasive use of work activities in modern organization requires employees to compare with their peers or opponents and compare the self over time. Due to the interdependent nature of Chinese organization, supervisors make members comparing with one another's better performance to enhance their work or comparing with one another's worse performance to introspect themselves, or hope subordinates getting the self-reflection from the comparison of their own past similar experience over time. The emergence of the word 'comparison' captures the features of selfenhancement from comparison in the lateral and vertical dimension.

A review of the tradition Western research on comparison reveals that comparison is often defined as a basic human motive (Pettigrew, 1967), and most researchers take a two dimensional view and conceptualize comparison as acquiring information about the self from others by the self-evaluation motive on opinions and abilities (Festinger, 1954; Gibbons \& Buunk, 1999; Buunk \& Gibbons, 2007). On the other hand, scholars have observed that Chinese people seem to view comparison including comparing with others in the lateral dimension and comparing with self over time in the vertical dimension that do not lie at the opposite ends of a single dimension. Based on their strong cognitive tendency about acceptance of contradiction, Chinese people form a way of dialectical thinking (Peng \& Nisbett, 1999). Taking this independence view as our departure, we define comparison in the lateral dimension and comparison in the vertical dimension as two distinct concepts that represent individuals' different beliefs and attitudes toward the nature of their relationship with others. The purpose of this study is threefold:

- to investigate the meanings of lateral comparison and vertical comparison as two individual trait/state constructs which supervisors use to motivate their subordinates in the Chinese context;

- to develop scales to measure them; and 
- to report validation studies that demonstrate the utility of these new scales.

In the following pages, we first propose that cultural upbringing people are especially capable of cognitively reconciling the seemingly mutually exclusive meanings of lateral comparison and vertical comparison in the Chinese context, adopting the contextualization approach proposed by Farh and his colleague (Farh, Cannella \& Lee, 2006) in Theory. We then report the results from following two studies that demonstrate the psychometric properties of the new scale, and discuss the theoretical and empirical implication of our findings in Section 3 and 4. We further provide alternative explanations for results in Section 5 and maintain the theoretical significance, limitation and practical significance of this research in Section 6, 7 and 8.

\section{Comparison in the Lateral and Vertical Dimension: Conceptualization and Empirical Finding}

Comparison is often associated with telling the same and different point between things and getting an objective comprehensive understanding in social relating such as work and family. The construct of comparison has received much attention from researchers in social and health psychology, psychopathology, and organizational behavior in the West (Fliessbach et al., 2007; Furnham \& Brewin, 1988; Buunk \& Gibbons, 2007; Gilbert \& Allan, 1994; Gilbert et al., 1995; Richins, 1991; Greenberg, Ashton-James \& Ashkanasy, 2007). In social comparison theory, Festinger (1954) initially defined social comparison as individuals evaluate their own opinions and abilities by comparing themselves with others for the purpose of uncertainty reducing and self-enhancing. The majority of this research advocates a two-dimensional view of comparison. For example, in an early version of this scale, Gilbert and Allan (1994) posited a bipolar construct of the five social comparisons on global dimensions relevant to relative judgments of rank and status. They further expanded a new bipolar scale to social comparison within the semantic differential approach to investigate differences in rank and group fit judgments for clinical rating (Allan \& Gilbert, 1995). What's more, social comparison has different views of the world and others. Gibbons and Buunk (1999) distinguished between two types of social comparison as opinion and ability with Dutch and American sample. Their study showed that American has higher level of comparison than in the Northern European such as people in Denmark and the Netherlands, and women have modestly but significantly higher level of comparison than that of the man.

Another approach to social comparison emphasizes the amount and direction of comparison. Research in this tradition has shown that people with the desire or need for self-enhancement tend to make upward comparison or downward comparison (Buunk \& Gibbons, 2007). Upward comparison refers to individuals whose "upward drive" (Suls \& Miller, 1977) is salient and have interest in doing better, prefer to confirm their similarity to others better-off and to learn from such others in their comparison (Buunk, 1995; Buunk, Schaufeli \& Ybema, 1994; Mussweiler, 
Gabriel \& Bodenhausen, 2000). For instance, Gerrard, Gibbons, Stock, Lune and Cleveland (2005) found smokers who compared with other success at quitting smoking were more likely to succeed at quitting themselves. Downward comparison is that individuals in coping with problems, such as feeling threatened on a particular dimension or willing to enhance their subjective well-being, tend to compare with others who are thought to be worse off on the same dimension (Hakmiller, 1966; Brickman \& Bulman, 1977). Wills (1981) identified two forms of downward comparison: active downward comparison, which involves derogating, verbal harming and physically humiliating to the created target; and passive downward comparison, which includes responding to the information about other's worse off. For example, Wood, Taylor and Lichtman (1985) reported that most female breast cancer patients felt much better when downward comparing with other worse-off victims. The similar finding was evidenced in a considerable body of research about downward social comparison among populations facing a health threat and mentally handicapped, such as those with cancer (van der Zee, Agterberg, Peeters, Mooi \& Schellekens, 1996), arthritis (Giorgino, Blaloc, Devellis, DeVellis, Keefe \& Jordan, 1994), chronic pain (Affleck, Tennen, Pfeiffer, Fifield \& Rowe, 1987; Tennen, McKee \& Affleck, 2000) and stress (Gibbons \& Boren, 1985). Embedded in this approach is the assumption that upward comparison is the opposite of downward comparison.

Deeply rooted in European American ways of thinking, people with Aristotelian logic tend to polarize contradictory perspectives, viewing upward comparison/downward comparison as two opposing forces in the lateral dimension. However, little research mentioned about temporal comparison, which refers to the improving or declining of behavioral outcomes over time. Albert (1977) emphasized two traits of temporal comparison:

- receiving the behavioral feedback of self, without relative to others;

- knowing the self in time series.

In order to support the perceptions of personal improvement, people between young and middle age tend to believe that they are happier (Brickman, Coates \& Janoff-Bulman, 1978), make more improvement (Fleeson \& Heckhausen, 1997), feel better of the selves (Baumeister, Dori \& Hastings, 1998; Higgins, 1996; Sedikides, 1993) than they were in the past. Wilson and Ross (2001) further proposed that people favor the recent past self but depreciate the distant past self and evaluate themselves on an absolute scale rather than on a relative one. For instance, a middle aged female employee well recognizes that she made progress in her work since her mid-20s. At the same time, she may judge her performance now to be much better than her peers.

As Wilson and Ross (2001) noted, self-appraisal process may change culturally. The Chinese way of dealing with self-evaluation and self-enhancement is quite different. The Confucius analect, for example, assumes that seeing another better than oneself, one tries to emulate him; seeing another worse than oneself, one tries to introspect. It advocates a dialectical 
approach - retaining the self-enhancement by learning from the targets and adapting the self in the upward comparison, examining oneself and introspecting from the worse off target in the downward comparison. In addition, Chinese participants with the dialectical thinking also get the introspection from themselves by comparing their current opinion and ability with their previous successful or failed experience in the vertical temporal dimension. Dialectical thinking is a cognitive tendency toward acceptance of contradiction, and this tendency has been found to be much stronger in the Chinese context (Peng \& Nisbett, 1999; Spencer-Rodgers, Boucher, Mori, Wang \& Peng, 2009).

An accumulating number of researches about comparison in the lateral dimension and vertical dimension were evidenced in the Chinese context. Due to the collectivist culture, many people in China with a salient interdependent self-construal (Markus \& Kitayama, 1991) tend to think and behave in ways that they emphasize their connectedness to important roles and status (Cross, Bacon \& Morris, 2000), belonging and fitting, and highly depend on the judgment or social norms from others and the surrounding context (Cross et al., 2000). Seeing the person as more connected and less differentiated from others, individuals primarily on independence are always involved in comparing with some excellent models/competent counterparts in the interpersonal interaction and child rearing. In the self-evaluation maintenance model, Tesser (1988) found that men with interdependence maintain or increase positive self-evaluation when a close other have better performance in the low relevant task, whereas they perceive the threat and greater potential pain in self-evaluation from comparison with a close other with better performance in the high relevant task. Consistency evidence can be found in Brenner's (1973) research of a group for the task of reading words, individuals have a difficult time remembering the words read just before their own turns and before a friend's turns. Similar finding was supported in the research of Chinese child-rearing pattern, for instance, Fung (1999) reported that Tai Wan parents use opportunity education (jihuijiaoyu) to exposure children to the "well - behaved" and "normal" children or siblings. In her study, after listening to her cousin playing the piano, the girl spontaneously and naturally "wants to be as good as she" and works harder to play. In the upward comparison with the competent peers or opponents, only the motive of self-improvement is salient (Buunk \& Gibbon, 2007), participants who are interdependent have an interest in doing better.

Further, downward comparison in the Chinese context works as a way of motivation. Fung (1999) reported another type of opportunity education - downward comparison the Chinese caretakers use. Observing other peers' transgression or unfavorable behavior, parents emphasize the social disapproval and reinforcing the rightness of behavior toward their children though they are well performed. In other words, to prevent the child's misbehavior, parents make explicit reference by threatening, scolding, shaming, and physical punishment (Ho, 1986, 1996; Chao, 1994), such as suggesting that the whole family would go to the playground without taking the child, or spanking the child if he/she behaves like the 
transgressed sibling. Thus, the child reaches the understanding that he/she should do better than the misbehaved peer.

To reflect the meanings of comparison in the vertical temporal dimension of the Chinese context to describe the personal introspection, we define the introspection from this comparison as stable psychological state, which represents the configuration of a whole personality and culture. Comparison in the vertical dimension is defined as comparing one's current opinion and ability with his/her past success or failure. When Japanese subjects with independent-self perform worse than their opponents, they are more confident and more selfenhanced than Americans with dependent-self in their ability after failure feedback (Schwartz \& Smith, 1976; Shikanai, 1978; Davis \& Stephan, 1980). In the high context communication, Hall (1989) maintained that the meaning is conveyed by multichanneled communicative system (including verbal, nonverbal, and paralinguistic) and embedded in multiple contexts of everyday moral socialization. Due to the preprogrammed information hidden between the receiver and the setting (Shapiro, Von Glinow \& Xiao, 2007; Adair, Buchan, Chan \& Liu, 2013), Easterners such as Chinese in the high communicating context capture the subtle meaning (Kittler, Rygl \& Mackinnon, 2011) and get the introspection from others' implicit evaluation or judgment to them. In the workplace, for example, the supervisor's silence toward the subordinate's normal performance is to convey the meaning that "I'm not satisfied about your work"; "what you do is worse than your previous performance", to maintain face-saving and conflict-avoidance (Ting-Toomey, 1988) and to expect the man to introspect his fault. Sometimes, intentional sarcasms or depreciation, which supervisors use toward the subordinates' unpleasant behavioral outcome is a motivational approach, such as "are you a man? I think you are a teddy bear. If you are afraid of exposuring to the sun, you are not a soldier, just go home!"; "You are suck this time, you did better last time". The purpose is to promote the subordinates' self-enhancement in a short time. Fung (1999) found children get self-introspection and adept their behavior from their vertical comparison experience that withdrawing of love and punishment toward their misdeeds and getting reward toward their normal behavior. Therefore, the extent to which a behavior indicates comparison in a lateral or vertical dimension varies according to the cultural context in which it occurs. The question we address in the present study concerns how people evaluate and motivate themselves when they have both of these information sources at their disposal, that is, when they know that they have progressed over time, and when they are superior or inferior to others. 


\section{Study 1: Scale Development}

\subsection{Preprocessing}

\subsubsection{Item Generation}

In study 1 , we used an open-ended questionnaire and a semi-structured interview to develop comparison scale. An opened-ended survey sample was used to generate item pool for comparison scale, and the interview participants were used to match and reexamine the items from questionnaire sample. The items were then screened and selected, resulting in a 7-item scale.

\subsubsection{Sample and Procedure}

In the first stage, the sample consisted of 35 Chinese employees from 35 enterprises (including state-owned, joined venture, private, family enterprises and institutions) in nine cities (Shen Zhen, Guang Zhou, Cheng Du, Nan Jing, Bei Jing, Shen Yang, Harbin, and Xi'an) of China. The group was 30 percent male, 50 percent college education, 47.8 percent white collars and had an average age of 32 years with 8.7 years of working experience. We asked the participants to list 7-8 statements best described comparison that supervisors used toward them in the workplace. We obtained from this process a total of 274 statements describing types of comparison supervisors used (valid response rate is $98 \%$, each describes 7.84 items).

In the second stage, the sample consisted of 9 supervisors and subordinates dyadic $(n=18)$ from nine Chinese enterprises/institutions. The group was 55 percent male, 55 percent college education, 50 percent white collars and had an average age of 33 years with 8.9 years of working experience. We used the semi-structured interview toward the participants to explore the events of comparison that supervisors applied to their subordinates. In this part, participants were required to give the definition of comparison, and we further provided its formal definition from dictionary (94 percent participants provided same definition of comparison as it in the dictionary). Then they stated the experience of comparison. We obtained from this process a total of 15 stories describing comparison between supervisors and subordinates.

In as much as our purpose in using 35 respondents and 18 participants was to obtain a wide and diverse range of feedback and to overcome the sub-culture effects of a general culture, we were relatively unconcerned about only using convenience 18 samples because of theoretical saturation (Morse, 1995; Bloor \& Wood, 2006) when we did 11 interviews. 


\subsubsection{Item Screen}

We followed the procedures outlined by Farh, Earley and Lin (1997) in item screening. We engaged in a three-stage sorting process. In the first stage, we carefully combined very similar items into one category in terms of two criterions:

- the descriptions that participants express should have clear meaning;

- the descriptions should be the comparison behavior toward subordinates whom supervisors tend to motivate.

Items that could be carefully combined very similar items with these items. Four researchers eliminated overly vague items in which the relationship between the item and comparison was very unclear. We developed 239 preliminary items that reflected comparison.

In the next step, two researchers reached a consensus about grouping these items into two categories based on the comparison patterns:

- comparison with the opponent/peer(s) in a lateral dimension; and

- comparison with one's past similar experience in a vertical dimension.

In the third sorting stage, we selected 6 to 10 statements from each category, choosing the most frequently mentioned items, and matched them with 15 stories from the interview. The 7 representative statements constituted our original comparison items.

\subsection{Overview of Goals and Methods}

Against this backdrop, the goal of this project was to develop and test the psychometric properties of comparison scale in the Chinese organizational context. The procedures are described collectively given their similarities. In this part, we tested the factor structure of comparison. Following the procedures in recent scale development studies (e.g., Wei, Álvarez, $\mathrm{Ku}$, Russell \& Bonett, 2010), we randomly split the sample into two. The first half of the sample $(n=210)$ was used for exploratory factor analysis, and the remaining sample $(n=211)$ was used for confirmatory factor analysis in Study 1.

\subsection{Scale Testing I -Exploratory Factor Analysis}

\subsubsection{Sample and Procedure}

Participants were 210 employees from various organizations in Harbin, Beijing, Shanghai and Shenzhen, People's Republic of China. The median age of employees was 26-35, 6-10 years of organization tenure, 50 percent of them were male, and over 90 percent had college or a more 
advanced degree. The companies represented two broad industry groups, manufacturing and service.

In the survey, comparison 7-items questionnaire is used to subordinates. All respondents evaluated the extent to which they agreed with the statements using a 6-point Likert scale (1 = strongly disagree, 6 = strongly agree), sealed the completed questionnaires in envelopes and returned them to the human resource managers of the companies or to the researchers directly. We used six-point Likert point scale because studies have shown that Chinese tend to choose the mid-point of the scale due to the Confucian doctrine of the mean' value (Chiu \& Yang, 1987). By eliminating a mid-point, we hoped to reduce this central tendency bias.

\subsubsection{Results}

Exploratory factor analysis (principle factor analysis with varimax rotation) of the 7-items scale yielded a two-factor model that explained 72.03 percent of variance, with the two factors explaining 38.11 percent, 33.92 percent of the total variance, respectively. To arrive at a meaningful and interpretable factor structure, we applied the following four criteria to screen items. First, the item must have a minimum loading of .40 or greater on a factor. Secondly, the item must have low cross loading on other factors. Thirdly, the content of the items retained must be consistent with those of the other items loaded on the same factor (Netemeyer, Bearden, \& Sharma., 2003). Fourth, the CITC (Corrected Item-Total Correlation) of each item must have a minimum value of 0.3 or greater. Using this procedure, we retained 6 items for the final scale (see Table 1), accounting for 76.48 percent of the total variance, with two factors explaining 39.77 percent, 36.71 percent of the total variance, respectively. We dropped one items with content that was inconsistent with other items loading on the same factor and low value than 0.3 of CITC.

\begin{tabular}{|c|c|c|c|}
\hline Items & $\begin{array}{l}\text { Lateral } \\
\text { Comparison }\end{array}$ & $\begin{array}{l}\text { Vertical } \\
\text { Comparison }\end{array}$ & CITC \\
\hline 1. The supervisor compares me with a well-performed peer/opponent. & .68 & .34 & .59 \\
\hline 2.The supervisor compares me with a worse-off peer/opponent. & .91 & -.17 & .32 \\
\hline 3. The supervisor announces the list of reward or punishment. & .84 & .34 & .75 \\
\hline $\begin{array}{l}\text { 4. The supervisor depreciates me for my work result by comparing } \\
\text { with my past good working. }\end{array}$ & .34 & .81 & .67 \\
\hline $\begin{array}{l}\text { 5. The supervisor criticizes me for my work result by comparing with } \\
\text { my past good working. }\end{array}$ & .23 & .85 & .58 \\
\hline 6. The supervisor recognizes me for the improvement of my work. & .23 & .81 & .36 \\
\hline
\end{tabular}

Notes:

$N=210$ including subordinates dyads.

CITC of each item must have a minimum value of 0.3 or greater.

Table 1. Factor structure and loadings of lateral comparison and vertical comparison scales

Table 1 shows that the comparison scale consisted of two distinct factors. The two factors or dimensions are labeled and interpreted as follows: 
- Lateral Comparison. This dimension refers to a supervisor comparing the subordinate or group member with another group of excellent peer/member when they have low performance at work or lack of confidence and interest, or comparing the subordinate with the worse off targets to get the self-enhancement and learn from their failure. It consists of three items with a Cronbach alpha of .79.

- Vertical Comparison. This dimension indicates that a subordinate get introspection or self-reflection from comparing their current behavior with their previous similar experience over time. In the workplace, the supervisor intentionally depreciates or criticizes subordinates toward their current behavior by comparing with their past better behavior over time, such as comparing the employees' misdeeds or unpleasant behavioral outcomes with their past good performance to express his/her unsatisfaction toward the employer and expect the member to introspect and strive for excellence. It consists of three items with a Cronbach alpha of .82.

Results from the reliability analysis indicate that both scale had high reliabilities. The correlation between the two scales was significant $(r=.35, p<0.01)$. These results provide initial evidence supporting our conceptual treatment of lateral comparison and vertical comparison as two constructs that people are exposure to some excellent models in social comparison, or they get introspection by comparing with their previous similar success or failure over time.

\subsection{Scale Testing II - Confirmative Factor Analysis}

\subsubsection{Sample and Procedure}

Participants were from several organizations in Harbin, Beijing, Shanghai and Shenzhen, People's Republic of China. The 6-item survey was distributed to 211 subordinates. The employees' age ranged from 20-55, with 60 percent of them having over 10 years of working experience, 57 percent of them were male, and approximately 78 percent of them had college and above education.

\subsubsection{Results}

We conducted a CFA to test the construct validity of the lateral comparison and vertical comparison. The CFA reveals good fit indices for the two-factor model of the 6-item scale, $x^{2}=21.15, d f=7, \mathrm{p}<0.01 ; \mathrm{CFI}=0.97, \mathrm{IFI}=0.97, \mathrm{NFI}=0.95, \mathrm{RMSEA}=0.09$, which was close to the recommended cutoff value of .08 , but a poor fit for the one-factor model: $x^{2}=77.21, d f=8$, $\mathrm{p}<0.01 ; \mathrm{CFI}=0.85, \mathrm{IFI}=0.85, \mathrm{NFI}=0.84, \mathrm{RMSEA}=0.20 ; \Delta x^{2}=56.06, \mathrm{p}<0.01$. These results 
suggest that the two-factor model fits our data. The correlation between these two subscales is moderate in both studies $(r=.35, \mathrm{p}<0.01, \mathrm{n}=210 ; r=.39, \mathrm{p}<0.01, \mathrm{n}=211)$, suggesting that lateral comparison and vertical comparison are two distinct but related constructs. These results support our conceptualization of comparison as including two distinct components in the Chinese organizational context.

\section{Study 2: A Field Study}

So far we have demonstrated the construct validity and the distinctiveness of lateral comparison and vertical comparison. To further test the scales' predictive validity, we conducted a field study in Chinese organizations. As comparison with peers in a lateral dimension and comparison with self in a vertical temporal dimension are treated as relative stable motivational approaches in our study, we wanted to examine their effects on employee task performance and organizational citizenship behavior (OCB).

Task performance and OCB are the two most crucial indicators of employee output in organizations. Task performance (or in-role performance) contributes directly through the production of goods and services, whereas OCB (or extra-role/contextual performance) contributes indirectly to organizational success by maintaining or promoting the organizational, social, or psychological environment in which the technical core is embedded (e.g., Borman \& Motowidlo, 1993; Katz \& Kahn, 1978; Organ, 1997). Typical OCBs in Chinese organizations include helping and cooperating with colleagues, making constructive suggestions to improve the operation of the company, maintaining interpersonal harmony with group members, increasing self-learning to enhance the quality of work outputs, and protecting the organization reputation (Farh et al., 1997). As both task performance and OCB contribute to overall organizational effectiveness, we include both in the study.

While Festinger's (1954) article did not explicitly define comparison intended to enhance selfconcept, self-enhancement varies as a function of the context in which the comparison occurs (Suls \& Millers, 1977) and manifests as the promotion of performance. A brief review of comparison literature indicates that the construct domains of the most popular social comparison measure (Gibbons \& Buunk, 1999) - opinions and abilities are the predictors for performance. One aim of comparing with others is to learn more about their abilities and to improve (Brickman \& Bulman, 1977; Taylor \& Lobel, 1989). For example, students who are in the upward comparing environment have better academic performance (Frey \& Ruble, 1985; Huguet, Dumas, Monteil \& Genestoux, 2001). In the gift-exchange and fair wage comparison experiments, Fehr, Kirchsteiger and Riedl (1993) showed that the 'horizontal' comparisons among employees in a group determine the workers' effort decision. Similar finding was reported in Simon and his colleagues' (2010) research, comparison with the unbalanced wages from peers would undermine workers' effort levels due to an aversion against intentional wage 
discrimination. Consistent with these findings, evidence also finds a relative strong and stable relationship between setting a good model for members and OCB in the research of transformational leadership behaviors (Podsakoff, MacKenzie, Moorman \& Fetter, 1990; Podsakoff, MacKenzie \& Bommer, 1996), and positive relationship between fairness perception, fair treatment in the comparison and OCB (Schappe, 1998; Williams, Pitre \& Zainuba, 2002). Therefore, we hypothesize:

Hypothesis 1: Supervisor's lateral comparison approach will be positively related to both task performance and $O C B$.

The lack of prior research makes prediction about temporal comparison information more difficult. Only a few studies have examined the interplay between temporal and social comparison information, and some have examined relative preferences for obtaining social and temporal comparison information following task performance. For instance, in one experimentally-manipulated research, Levine and Greene (1984) reported that subjects had done better on the problems in the intrapersonal condition when they noticed their peers' previous good performance which is fictitious. Similar finding was reported in Ruble and Flett' $s$ (1988) research, older and high-ability children are more likely to engage autonomous comparison and social comparison information to enhance their self-evaluation than younger and low or medium-ability children are. Further, Zell and Alicke (2009) proposed that temporal comparison information influenced self-evaluations at each level of social comparison. When responding $O C B$, people's subsequent emotional and behavioral responses depend on their evaluation of the situation that elicited their OCB for the causes of the demands (Spector \& Fox, 2010), such as help organization, get benefit, be promotion. According to Zell and Alicke (2009), people involve temporal improvement to enhance their self-evaluation when it is coupled with gains in social status. In addition, studies of motives for OCB (Rioux \& Penner., 2001) and more generally, volunteering (Finkelstein \& Brannick., 2007), clearly show that selfserving motives and self-evaluation can be involved. Therefore, we hypothesize:

Hypothesis 2: Supervisor's vertical comparison approach will be positively related to both task performance and $O C B$.

\subsection{Sample and procedure}

The survey sample used in this study included 269 supervisor-subordinate dyads from several organizations in Chang Chun and Guang Zhou, People's Republic of China. The employees' age ranged from $20-55$, with $68 \%$ percent of them having over 10 years of working experience, 43 percent of them were male, and approximately 80 percent of them had college and above education. The supervisors' age ranged from 25-55, with 80 percent of them having over 10 
years of working experience, 79 percent of them were male, and approximately 74 percent of them had college and above education.

\subsection{Measures}

We asked subordinates to complete the comparison scale that they perceive and their supervisors to evaluate their direct subordinates' task performance and organizational citizenship behavior. Thus, our independent and dependent measures came from different sources, which minimized the potential common method error (Podsakoff, Mackenzie, Podsakoff \& Lee, 2003).

Two-dimensional comparison. The 6-item scale from Study 2 was used to measure comparison (lateral comparison and vertical comparison) that they use toward their subordinates. The alphas of the two dimensions (i.e., lateral comparison and vertical comparison) were 0.80 and 0.73 respectively. These reliability measures are similar to the ones obtained in Study 2 . We used six-point Likert point scale $(1=$ strongly disagree, $6=$ strongly agree $)$ to reduce the central tendency bias.

Task performance. Supervisors rated the task performance of their subordinates, using a fouritem scale developed by Chen, Tsui and Farh (2002). Sample items included, 'S/he makes significant contribution to the overall performance of our work unit' and 'S/he makes significant contribution to the overall performance of our work unit'. A 6-point Likert scale was used to measure task performance ( $1=$ strongly disagree, $6=$ strongly agree). The reliability coefficient for this measure was 0.80 .

Organizational citizenship behavior. Supervisors also rated their subordinates' OCB. We used Farh et al.'s (1997) OCB scale due to its origination in the Chinese context. This scale comprises of five subscales (altruism, conscientiousness, civic virtue, interpersonal harmony, and protecting company resources) with a total of 20 items ( 7 items are reverse scored). Given the correlations among the OCB dimensions (ranging from 0.14 to $0.79, p<0.05$ ) and our theoretical focus on the overall $O C B$, we use the mean of all items to form a composite index of OCB by collapsing its five dimensions from previous studies (Hui, Law \& Chen, 1999; Wong, Ngo \& Wong, 2006). The reliability coefficient (Cronbach's alpha) for the scale was 0.91.

Demographic variables. We again included the supervisors and subordinates' gender, age, education, working experience and enterprises as control variables. 


\subsection{Results}

Hypothesis testing. Table 2 presents the mean, standard deviation, and correlations of the variables of interest. It can be seen that lateral comparison is positively related to task performance $(r=0.26, p<0.01)$, and lateral comparison is negatively related to organizational citizenship behavior $(r=-0.46, p<0.01)$. These results provide partially preliminary evidence for $\mathrm{H} 1$. Vertical comparison is positively related to task performance $(r$ $=0.13, p<0.05)$, and vertical comparison is positively related to OCB $(r=0.40, p<0.01)$. These results provide preliminary evidence for $\mathrm{H} 2$.

\begin{tabular}{|c|c|c|c|c|c|c|c|c|c|c|c|c|c|}
\hline Variables & Mean & s.d & 1 & 2 & 3 & 4 & 5 & 6 & 7 & 8 & 9 & 10 & 11 \\
\hline $\begin{array}{c}\text { 1.Subordinates } \\
\text { age }\end{array}$ & 3.57 & 1.03 & & & & & & & & & & & \\
\hline $\begin{array}{c}\text { 2.Subordinates } \\
\text { gender }\end{array}$ & 0.57 & 0.50 & 0.06 & & & & & & & & & & \\
\hline $\begin{array}{l}\text { 3.Subordinates } \\
\text { education }\end{array}$ & 2.84 & 0.59 & -0.07 & 0.05 & & & & & & & & & \\
\hline $\begin{array}{l}\text { 4.Subordinates } \\
\text { working } \\
\text { experience }\end{array}$ & 4.06 & 1.20 & $0.76^{* *}$ & 0.12 & 0.05 & & & & & & & & \\
\hline $\begin{array}{c}\text { 5. Supervisor } \\
\text { age }\end{array}$ & 4.01 & 0.80 & $0.26^{* *}$ & $-0.18^{* *}$ & $0.23^{* *}$ & $0.33^{* *}$ & & & & & & & \\
\hline $\begin{array}{c}\text { 6.Supervisor } \\
\text { gender }\end{array}$ & 0.79 & 0.41 & 0.07 & $0.38^{* *}$ & $0.28^{* *}$ & 0.12 & 0.08 & & & & & & \\
\hline $\begin{array}{l}\text { 7.Supervisor } \\
\text { education }\end{array}$ & 2.74 & 0.72 & -0.05 & -0.04 & $0.43^{* *}$ & 0.09 & $0.34^{* *}$ & $0.15^{*}$ & & & & & \\
\hline $\begin{array}{l}\text { 8.Supervisor } \\
\text { working } \\
\text { experience }\end{array}$ & 3.58 & 0.80 & $0.23^{* *}$ & 0.02 & $0.16^{* *}$ & $0.34^{* *}$ & $0.67^{* *}$ & $0.15^{*}$ & $0.49^{* *}$ & & & & \\
\hline 9. Enterprises & 1.87 & 1.39 & $-0.27^{* *}$ & $-0.38^{* *}$ & $-0.23^{* *}$ & $-0.40^{* *}$ & $-0.22^{* *}$ & $-0.50^{* *}$ & -0.05 & $-0.27^{* *}$ & & & \\
\hline $\begin{array}{l}\text { 10.Lateral } \\
\text { comparison }\end{array}$ & 3.48 & 0.72 & $-0.13^{*}$ & -0.12 & $-0.24^{* *}$ & $-0.25^{* *}$ & $-0.36^{* *}$ & -0.10 & $-0.27^{* *}$ & $-0.37^{* *}$ & 0.11 & & \\
\hline $\begin{array}{l}\text { 11.Vertical } \\
\text { comparison }\end{array}$ & 3.26 & 0.86 & -0.09 & 0.11 & 0.07 & -0.80 & $-0.23^{* *}$ & -0.09 & -0.05 & $-0.21^{* *}$ & 0.00 & 0.02 & \\
\hline $\begin{array}{c}\text { 12.Task } \\
\text { performance }\end{array}$ & 3.92 & 1.29 & $-0.13^{*}$ & $-0.19^{* *}$ & -0.02 & $-0.18^{* *}$ & -0.11 & $-0.15^{*}$ & -0.07 & $-0.15^{*}$ & $0.22^{* *}$ & $0.26^{* *}$ & $0.13^{*}$ \\
\hline $13.0 \mathrm{CB}$ & 4.79 & 0.71 & -0.03 & $0.14^{*}$ & 0.05 & 0.10 & 0.04 & 0.05 & -0.05 & 0.05 & -0.10 & $-0.46^{* *}$ & $0.40^{* *}$ \\
\hline
\end{tabular}

Table 2. Mean, standard deviations, and correlations of the variables

As supervisors rated the direct subordinates, we analyzed our data with multiple linear regression to test our hypothesis. We first enter the demographic variables of the subordinate (age, gender, education, work experience), followed by the demographic variables of the supervisor (age, gender, education, work experience, enterprise). In step 2, we entered the main effects of lateral comparison and vertical comparison, respectively. The results of this analysis are presented in Table 3.

Several noticeable findings can be seen from Table 3. First, the demographic variables (both supervisor and subordinate) explained 9 percent of the variance in task performance and 6 percent of the variance in OCB. Among the demographic, subordinate age and supervisor education had a negatively significant effect on subordinates' $O C B$, the type of enterprises had a positively significant effect on subordinates' task performance. 
Second, lateral comparison and vertical comparison explained significant amounts of additional variance in task performance $\left(\triangle R^{2}=15 \%, p<0.01\right)$ and in $O C B\left(\triangle R^{2}=41 \%, p<0.01\right)$, respectively. Among them, lateral comparison had a significant positive relationship with task performance $(\beta=0.24, p<0.01)$ but significant negative relationship with OCB $(\beta=-0.48$, $\mathrm{p}<0.01)$. Vertical comparison had a significant positive relationship with both task performance and $\mathrm{OCB}(\beta=0.14, p<0.05$ and $\beta=0.40, p<0.01)$, respectively. These results provide partially support for $\mathrm{H} 1$ and considerable support for $\mathrm{H} 2$.

\begin{tabular}{|c|c|c|c|c|}
\hline & \multicolumn{4}{|c|}{ Organizational citizenship behavior } \\
\hline Task performance & Model 1 & Model 2 & Model 1 & Model 2 \\
\hline Constant & $4.81^{* *}(0.69)$ & $1.31(1.08)$ & $4.22^{* *}(0.39)$ & $5.70^{* *}(0.49)$ \\
\hline \multicolumn{5}{|l|}{ Control variables } \\
\hline Subordinate age & $0.01(0.12)$ & $-0.01(0.11)$ & $-0.25^{*}(0.07)$ & $-0.20^{* *}(0.05)$ \\
\hline Subordinate gender & $-0.14^{*}(0.18)$ & $-0.11(0.18)$ & $0.13(0.10)$ & $-0.01(0.08)$ \\
\hline Subordinate education & $0.07(0.15)$ & $0.09(0.15)$ & $0.24(0.06)$ & $-0.07(0.07)$ \\
\hline Subordinate work experience & $-0.10(0.11)$ & $-0.05(0.10)$ & $0.04^{*}(0.07)$ & $0.15(0.05)$ \\
\hline Supervisor age & $-0.07(0.14)$ & $0.01(0.14)$ & $0.05(0.08)$ & $0.01(0.06)$ \\
\hline Supervisor gender & $-0.04(0.23)$ & $-0.02(0.23)$ & $-0.01(0.13)$ & $0.08(0.10)$ \\
\hline Supervisor education & $-0.06(0.14)$ & $-0.05(0.13)$ & $-0.15(0.08)$ & $-0.19^{* *}(0.06)$ \\
\hline Supervisor work experience & $-0.02(0.15)$ & $0.03(0.14)$ & $0.06(0.08)$ & $0.05(0.07)$ \\
\hline Enterprise & $0.11(0.07)$ & $0.16^{*}(0.07)$ & $0.02(0.04)$ & $-0.11(0.03)$ \\
\hline \multicolumn{5}{|l|}{ Predictors } \\
\hline Lateral comparison & & $0.24^{* *}(0.12)$ & & $-0.48^{* *}(0.05)$ \\
\hline Vertical comparison & & $0.14^{*}(0.09)$ & & $0.40^{* *}(0.04)$ \\
\hline$\triangle R^{2}$ & 0.09 & 0.15 & 0.06 & 0.41 \\
\hline Adjusted $\mathrm{R}^{2}$ & 0.06 & 0.11 & 0.03 & 0.39 \\
\hline Overall model F & $2.76^{* *}$ & $3.96^{* *}$ & 1.89 & $16.27^{* *}$ \\
\hline
\end{tabular}

Table 3. Results of Linear Regression for Study 2: effects of lateral comparison and vertical comparison on employees' task performance and OCB

\section{Discussion}

This study systematically investigated the role of lateral comparison and vertical comparison played in task performance and OCB. The results support our conceptualization that in the Chinese organization, comparison has two distinct but related components - lateral comparison and vertical comparison. Comparison is manifested through comparing with the competent others, or comparing with the worse-off others and ranking the employees' work result whereas vertical comparison is manifested in the meaning that opposites what the supervisor really wants to express to stimulate subordinates introspect from their past similar experience.

In the study we conducted, we found both lateral comparison and vertical comparison to be positively related to the task performance. We also found that vertical comparison to be positively related to OCB whereas the effect of lateral comparison was negatively significant. According to our theoretical arguments, vertical comparison is more positively relevant than 
lateral comparison in the in-role and extra-role performance. These findings are counterintuitive because the target of comparison is striving for excellence when comparing with competent opponents in a lateral dimension; however, we found negative effect of this variable on OCB. In contrast, OCB tended to focus on promoting the effective functioning of the organization, such as assist colleagues, maintain the interpersonal harmony and take challenging assignment (Farh et al., 1997). In other words, the results are more nuanced than our general understanding of comparison are used in ordinary usage.

However, these findings somewhat echo Chen's (Chen, Xie \& Chang, 2011) analysis that competiveness orientation can more successfully predict task performance than $\mathrm{OCB}$. The possible explanation as to why lateral comparison relates task performance positively but OCB negatively.

First, comparison often involves competing with others. When a subordinate receives such passive comparison with his/her coworker or opponent from the supervisor, he/she goes through the process of various emotions, such as envy, shame, anger, confidence, ambition, etc. For instance, a manager gave bonus to one salesman publicly due to over completion of the task, other coworkers compared their performance with him:

- he worked harder than me, so he deserved the reward. I will do better next time!

- His ability is worse than me, so he doesn't deserve the reward. I can do better.

- How did he achieve that! I want to learn from him.

- He really did good job, but I can do better. Perceiving the difference between the model and themselves, employees are inspired to competent with other or strive for excellence, but still unsatisfied about being compared with significant others.

Second, the target person feels unpleasant when passively receiving the comparison from the supervisor. Due to the "pain" of social comparison (Brickman \& Bulman, 1977), people who are not faring well sometimes curtail comparison and diminish their extra working efforts (Buunk, 1994; Gibbons, Benbow \& Gerrard, 1994). As Ruble and Frey (1991) maintained, competitionbased situations tend to foster the interest in social comparison for most people whereas performance-based situations are likely to promote it for some people. With the emotional resistance for such negative evaluation, the employee unrealized the expectation from the employer in a short time, thus, he/she promoted the task performance to meet the standard requirement but reluctant to do more to benefit the organization at the meantime, such as working longer, making constructive suggestion toward the work related problem and sharing work assignment for colleagues. However, the target person would enhance both the in-role performance and extra-role performance over the long term when he/she noticed the purpose of comparison that the supervisor used is promoting subordinates to be more competent. 
Third, an alternative explanation is older employees are more sensitive in confront with comparison. In study 2, subordinates age was negatively significant to OCB, and the employees over 36 were 51 percent in the sample. Therefore, older workers may be more reluctant to do more OCB after being compared with significant others because of face losing or shame arousal (Wong, Kim, Nguyen, Cheng \& Saw, 2014; Bedford \& Hwang, 2003; Li, Wang \& Fischer, 2004). Fourth, female employees in the sample were 57 percent. Albeit the negative relationship between subordinates gender and OCB is insignificant, we still need to consider the possibility that female workers may be more vulnerable when getting involved in comparison with well-off coworkers.

The findings that vertical comparison positively correlates both task performance and OCB are intriguing because, on the surface, they seem inconsistent with prior research that indicates merely a significant relationship between temporary comparison and task performance (Levine \& Greene, 1984; Ruble \& Flett, 1988). However, our study differs significantly that vertical temporal comparison positively affects the task performance and OCB.

\section{Contributions}

The present study makes several contributions to the understanding of comparison as a motivation approach. It is worth noting that the content manifested in our scales is different from that in the West in at least two important ways. First, our items capture the nature of motivating the one to be more excellent about lateral comparison and vertical comparison, while the Western literature uses opinion and ability in the aspect of evolution benefits (Gibbons \& Buunk, 1999; Buunk, 1995) to define or measure comparison nature, and treated temporal comparison as a description of self in a time dimension (Albert, 1977).

Second, items in our scale represent different rather than opposite view of comparison. In the Western literature, behavioral feedback has both temporal and social components where people inform by the progression or regression over time and the time of being superior or inferior to others (Zell \& Alicke, 2009), but we still know little about how people use social and temporal comparison when both data sources are available for self-evaluation. The present research in the Chinese context broadens the perspective of conceptualizing lateral comparison and vertical comparison that could have profound influence on future research.

Further, we expand theorization about comparison, explaining what mechanisms make comparison influential in receiving behavioral feedback from related others and self. It works not only as a motivational approach that supervisors apply to evoke subordinates to pursue excellence, but also the development of a relationship with certain levels of emotion and Chinese supervisor-subordinate relations. This conceptualization of comparison allows 
researchers to recognize and study the evolution of comparison within teams and organizations.

This is one of the few studies that empirically links social and temporal comparison construct to performance and OCB. As a result of the multiple approaches (qualitative and field study), we employed the field study to validate and test our proposed lateral and vertical comparison as a motivational approach. Thus, our study is theoretically grounded and empirically rigorous.

The development of the valid lateral comparison and vertical comparison scales will facilitate more future organization research. More systematic studies can be conducted to examine the common and unique antecedents and consequences for lateral comparison and vertical comparison, thus establishing a nomological network for these two constructs. For example, beyond understanding the motivation process across cultures, do individual attribute lateral comparison and vertical comparison as the motivation approach differently in different cultures? Also, previous research has shown that people who have stronger comparison will yield higher performance than people who are not strong on orientation.

Moreover, we might be able to further our theoretical development regarding lateral comparison and vertical comparison, so as to examine their emotion mechanism, such as the emotion of anger, envy and shame, and to examine their moderating effects on the various relationships among important organizational variables, such as the association between supervisor-subordinate relationship and work performance, the relationship between close distance and job engagement. The introduction of this scale opens an avenue to re-examine many organizational behavior and human resource issues, which in turn could bring fresh perspectives and shed light on previous puzzling phenomena, such as why the depreciation of one's current work related behavior in lateral comparison works effectively in motivating the task performance of the collectively Chinese employees. It could be because in a culture stressing personal modesty, the use of negative or positive phrasing is connotatively different in Chinese than it is in English in many cases. It is common in the Chinese language of small negative attributes to be expressed using an exaggerated negation or an ironic identification as a motivational approach to inspire the target person to be more competent in work. It is therefore not surprising that when subjects were asked to describe motivated behavior, they identified some depreciated behaviors representing motivation. The fact that negative items was heavily used to describe stimulating for excellence. Thus, these employees get used to express the positive attributes as a negative wording for self to maintain the interpersonal harmony with others, and that lateral comparison and vertical comparison from their supervisors facilitate their motivation to perform unexpectedly. 


\section{Limitation}

We recognize on the other hand that this research has limitations. One limitation is related to the cross-sectional data at one point in time of this survey study, which prevents us from inferring causality of our findings. For example, while we found that vertical comparison was positively related to in-role and extra-role performance, in our approach, the direction of the cause and effect is not certain. Though we observed that lateral comparison was positively related to in role performance and negatively related to extra-role performance, the cause and effect could be different in a long term. Studies with a longitudinal design will be helpful to provide more direct evidence.

Given our conceptualization of lateral comparison and vertical comparison in the Chinese organizational context, we limited our effects to examining just a simple relationship from the quality of lateral comparison and vertical comparison to in-role and extra-role performance. Future research should expand our model to include more variables for examining moderating and mediating effects. For instance, making positive comparison, or making any comparisons at all, self-esteem, supervisor-subordinate relationship, close distance, personality may be the important moderating variables, and the emotion of anger, shame, envy may be crucial mediating variables in the motivating process. Another trend to expand our theoretical model is to examine the antecedents of comparison, such as personality. In a study of hotel consumption, for example, guests with different personality vary their consumption emotions and levels of social comparison (Jani \& Han, 2013). Therefore, in our theoretical model, what personality traits supervisors have tend to use lateral comparison and vertical comparison to motivate their subordinates; what personality traits subordinates have are likely to behave beneficially after accepting such comparison.

Another limitation may be issues that are associated with our measures. First, our assessment of the comparison is a newly created measure that taps into intentions to engage in task performance and OCB on the employee's part. Although we were careful and took steps to develop a valid tool of measurement, and some of the analyses provided evidence of its validity, future research needs to further validate this scale.

Additional limitation, in our study, even though we tested the psychometric properties of the two scales with organizational employees in south and north part of China, we were not able to test them in other sample from different work and cultural contexts. More research is also needed to do with the generalizability of our findings. 


\section{Implications}

Our findings have important practical implications as well. The lateral comparison and vertical comparison scales can be used as motivation approach in evoking subordinates' potential ability and competence; people who score high on both scales will be better performers than those who score low on either or both scales. On the other hand, supervisors who are interested in enhancing more OCBs will need to focus more on vertical comparison as opposed to lateral comparison because lateral comparison does not appear to be a positive predictor of OCB. The measurement tool helps managers to motivate and predict employee behavior.

In summary, we believe that this study makes an important contribution to the comparison and motivation literature. It suggested that the Chinese people tend to receive the notion of lateral comparison and vertical comparison as striving for excellence and develop both lateral comparison and vertical comparison orientation simultaneously. This finding demonstrates that the culture with independent self and personal modesty might be defining characteristic of the Chinese employees who are invariably faced with lateral comparison and vertical comparison situation. Our findings can shed light on future research of Chinese managers as to how they apply such special motivational approach to encourage and evoke their capability to the work.

\section{References}

Adair, W.L., Buchan, N.R., Chan, X.-P., \& Liu, D. (2013). The challenge of nonverbal context in international business: A model of communication and social interaction style. Academy of International Business, Istanbul, Turey.

Affleck, G., Tennen, H., Pfeiffer, C., Fifield, J., \& Rowe, J. (1987). Downward comparison and coping with serious medical problems. American Journal of Orthopsychiatry, 57(4), 570. http://dx.doi.org/10.1111/j.1939-0025.1987.tb03572.x

Albert, S. (1977). Temporal comparison theory. Psychological Review, 84(6), 485. http://dx.doi.org/10.1037/0033-295X.84.6.485

Allan, S., \& Gilbert, P. (1995). A social comparison scale: Psychometric properties and relationship to psychopathology. Personality and Individual Differences, 19(3), 293-299. http://dx.doi.org/10.1016/0191-8869(95)00086-L

Baumeister, R.F., Dori, G.A. \& Hastings, S. (1998). Belongingness and temporal bracketing in personal accounts of changes in self-esteem. Journal of Research in Personality, 32(2), 222-235. http://dx.doi.org/10.1006/jrpe.1998.2218 
Bedford, O., \& Hwang, K.K. (2003). Guilt and Shame in Chinese Culture: A Crosscultural Framework from the Perspective of Morality and Identity. Journal for the Theory of Social Behaviour, 33(2), 127-144. http://dx.doi.org/10.1111/1468-5914.00210

Bloor, M., \& Wood, F. (2006). Keywords in qualitative methods: A vocabulary of research concepts. London: Sage.

Borman, W.C., \& Motowidlo, S. (1993). Expanding the criterion domain to include elements of contextual performance. In N. Schmidt, W. C. Borman, A. Howard, A. Kraut, D. Ilgen, B. Schneider, \& S. Zedeck (Eds.), Personnel Selection in Organizations (pp. 71-98). San Francisco: Jossey-Bass.

Brenner, M. (1973). The next-in-line effect. Journal of Verbal Learning and Verbal Behavior, 12(3), 320-323. http://dx.doi.org/10.1016/S0022-5371(73)80076-3

Brickman, P., \& Bulman, R.J. (1977). Pleasure and pain in social comparison. Social comparison processes: Theoretical and empirical perspectives, 149, 186.

Brickman, P., Coates, D., \& Janoff-Bulman, R. (1978). Lottery Winners and Accident Victims: Is Happiness Relative?. Journal of Personality \& Social Psychology, 36(8), 917.

http://dx.doi.org/10.1037/0022-3514.36.8.917

Buunk, A.P., \& Gibbons, F.X. (2007). Social comparison: The end of a theory and the emergence of a field. Organizational Behavior and Human Decision Processes, 102(1), 3-21. http://dx.doi.org/10.1016/j.obhdp.2006.09.007

Buunk, B.P. (1994). Social comparison processes under stress: Towards an integration of classic and recent perspectives. European Review of Social Psychology, 5(1), 211-241.

http://dx.doi.org/10.1080/14792779543000066

Buunk, B.P. (1995). Comparison direction and comparison dimension among disabled individuals: Toward a refined conceptualization of social comparison under stress. Personality and Social Psychology Bulletin, 21(4), 316-330.

http://dx.doi.org/10.1177/0146167295214002

Buunk, B.P., Schaufeli, W.B., \& Ybema, J.F. (1994). Burnout, uncertainty, and the desire for social comparison among nurses. Journal of Applied Social Psychology, 24(19), 1701-1718. http://dx.doi.org/10.1111/j.1559-1816.1994.tb01570.x

Chao, R.K. (1994). Beyond parental control and authoritarian parenting style: Understanding Chinese parenting through the cultural notion of training. Child Development, 65(4), 1111-1119. http://dx.doi.org/10.2307/1131308 
Chen, X.P., Xie, X., \& Chang, S. (2011). Cooperative and competitive orientation among Chinese people: scale development and validation. Management and Organization Review, 7(2), 353-379. http://dx.doi.org/10.1111/j.1740-8784.2011.00215.x

Chen, Z.X., Tsui, A.S., \& Farh, J.L. (2002). Loyalty to supervisor vs. organizational commitment: Relationships to employee performance in China. Journal of Occupational and Organizational Psychology, 75(3), 339-356. http://dx.doi.org/10.1348/096317902320369749

Chiu, C.-Y., \& Yang, C.-F. (1987). Chinese subjects' dilemmas: Humility and cognitive laziness as problems in using rating scales. Bulletin of the Hong Kong Psychological Society.

Cross, S.E., Bacon, P.L., \& Morris, M.L. (2000). The relational-interdependent self-construal and relationships. Journal of Personality and Social Psychology, 78(4), 791.

http://dx.doi.org/10.1037/0022-3514.78.4.791

Davis, M.H., \& Stephan, W.G. (1980). Attributions for exam performance. Journal of Applied Social Psychology, 10(3), 235-248. http://dx.doi.org/10.1111/j.1559-1816.1980.tb00706.x

Farh, J.-L., Earley, P.C., \& Lin, S.-C. (1997). Impetus for action: A cultural analysis of justice and organizational citizenship behavior in Chinese society. Administrative Science Quarterly, 42(3), 421-444. http://dx.doi.org/10.2307/2393733

Farh, J.L., Cannella, A.A., \& Lee, C. (2006). Approaches to scale development in Chinese management research. Management and Organization Review, 2(3), 301-318. http://dx.doi.org/10.1111/j.1740-8784.2006.00055.x

Fehr, E., Kirchsteiger, G., \& Riedl, A. (1993). Does fairness prevent market clearing? An experimental investigation. The Quarterly Journal of Economics, 108(2), 437-459. http://dx.doi.org/10.2307/2118338

Festinger, L. (1954). A theory of social comparison processes. Human Relations, 7(2), 117-140. http://dx.doi.org/10.1177/001872675400700202

Finkelstein, M.A., \& Brannick, M.T. (2007). Applying theories of institutional helping to informal volunteering: Motives, role identity, and prosocial personality. Social Behavior and Personality: An international journal, 35(1), 101-114. http://dx.doi.org/10.2224/sbp.2007.35.1.101

Fleeson, W., \& Heckhausen, J. (1997). More or less "me" in past, present, and future: perceived lifetime personality during adulthood. Psychology and Aging, 12(1), 125. http://dx.doi.org/10.1037/0882-7974.12.1.125 
Fliessbach, K., Weber, B., Trautner, P., Dohmen, T., Sunde, U., Elger, C.E. et al. (2007). Social comparison affects reward-related brain activity in the human ventral striatum. Science, 318(5854), 1305-1308. http://dx.doi.org/10.1126/science.1145876

Frey, K.S., \& Ruble, D.N. (1985). What children say when the teacher is not around: Conflicting goals in social comparison and performance assessment in the classroom. Journal of Personality and Social Psychology, 48(3), 550. http://dx.doi.org/10.1037/0022-3514.48.3.550

Fung, H. (1999). Becoming a moral child: The socialization of shame among young Chinese children. Ethos, 27(2), 180-209. http://dx.doi.org/10.1525/eth.1999.27.2.180

Furnham, A., \& Brewin, C.R. (1988). Social comparison and depression. The Journal of Genetic Psychology, 149(2), 191-198. http://dx.doi.org/10.1080/00221325.1988.10532152

Gächter, S., \& Thöni, C. (2010). Social comparison and performance: Experimental evidence on the fair wage-effort hypothesis. Journal of Economic Behavior \& Organization, 76(3), 531-543. http://dx.doi.org/10.1016/j.jebo.2010.08.008

Gerrard, M., Gibbons, F.X., Stock, M.L., Lune, L.S.V., \& Cleveland, M.J. (2005). Images of smokers and willingness to smoke among African American pre-adolescents: An application of the prototype/willingness model of adolescent health risk behavior to smoking initiation. Journal of Pediatric Psychology, 30(4), 305-318. http://dx.doi.org/10.1093/jpepsy/jsi026

Gibbons, F.X., Benbow, C.P., \& Gerrard, M. (1994). From top dog to bottom half: Social comparison strategies in response to poor performance. Journal of Personality and Social Psychology, 67(4), 638. http://dx.doi.org/10.1037/0022-3514.67.4.638

Gibbons, F.X., \& Buunk, B.P. (1999). Individual differences in social comparison: development of a scale of social comparison orientation. Journal of Personality and Social Psychology, 76(1), 129. http://dx.doi.org/10.1037/0022-3514.76.1.129

Gibbons, M.B. \& Boren, H. (1985). Stress reduction. A spectrum of strategies in pediatric oncology nursing. The Nursing clinics of North America, 20(1), 83-103.

Gilbert, P., \& Allan, S. (1994). Assertiveness, submissive behaviour and social comparison. British Journal of Clinical Psychology, 33(3), 295-306. http://dx.doi.org/10.1111/j.20448260.1994.tb01125.x

Gilbert, P., Price, J., \& Allan, S. (1995). Social comparison, social attractiveness and evolution: How might they be related?. New Ideas in Psychology, 13(2), 149-165.

http://dx.doi.org/10.1016/0732-118X(95)00002-X 
Giorgino, K.B., Blaloc, S.J., Devellis, R.F., DeVellis, B.M., Keefe, F.J., \& Jordan, J.M. (1994). Appraisal of and coping with arthritis-related problems in household activities, leisure activities, and pain management. Arthritis \& Rheumatism, 7(1), 20-28.

http://dx.doi.org/10.1002/art.1790070106

Greenberg, J., Ashton-James, C.E., \& Ashkanasy, N.M. (2007). Social comparison processes in organizations. Organizational Behavior and Human Decision Processes, 102(1), 22-41. http://dx.doi.org/10.1016/j.obhdp.2006.09.006

Hakmiller, K.L. (1966). Threat as a determinant of downward comparison. Journal of experimental social psychology, 1, 32-39. http://dx.doi.org/10.1016/0022-1031(66)90063-1

Hall, E.T. (1989). Beyond culture. Oxford: Anchor.

Higgins, E.T. (1996). The "self digest": self-knowledge serving self-regulatory functions. Journal of Personality and Social Psychology, 71(6), 1062. http://dx.doi.org/10.1037/00223514.71.6.1062

Ho, D.Y. (1986). Chinese patterns of socialization: A critical review. New York: Oxford University Press.

Ho, D.Y. (1996). Filial piety and its psychological consequences. The handbook of Chinese psychology (pp. 155-165).

Huguet, P., Dumas, F., Monteil, J.M., \& Genestoux, N. (2001). Social comparison choices in the classroom: Further evidence for students' upward comparison tendency and its beneficial impact on performance. European Journal of Social Psychology, 31(5), 557-578. http://dx.doi.org/10.1002/ejsp.81

Hui, C., Law, K.S., \& Chen, Z.X. (1999). A structural equation model of the effects of negative affectivity, leader-member exchange, and perceived job mobility on in-role and extra-role performance: A Chinese case. Organizational Behavior and Human Decision Processes, 77(1), 3-21. http://dx.doi.org/10.1006/obhd.1998.2812

Jani, D., \& Han, H. (2013). Personality, social comparison, consumption emotions, satisfaction, and behavioral intentions: How do these and other factors relate in a hotel setting?. International Journal of Contemporary Hospitality Management, 25(7), 970-993. http://dx.doi.org/10.1108/IJCHM-10-2012-0183

Katz, D., \& Kahn, R.L. (1978). The social psychology of organizations. Oxford: Wiley. 
Kittler, M.G., Rygl, D., \& Mackinnon, A. (2011). Special Review Article: Beyond culture or beyond control? Reviewing the use of Hall's high-/low-context concept. International Journal of Cross Cultural Management, 11(1), 63-82. http://dx.doi.org/10.1177/1470595811398797

Levine, J.M., \& Green, S.M. (1984). Acquisition of Relative Performance Information The Roles of Intrapersonal and Interpersonal Comparison. Personality and Social Psychology Bulletin, 10(3), 385-393. http://dx.doi.org/10.1177/0146167284103006

Li, J., Wang, L., \& Fischer, K. (2004). The organization of Chinese shame concepts?. Cognition and Emotion, 18(6), 767-797. http://dx.doi.org/10.1080/02699930341000202

Markus, H.R., \& Kitayama, S. (1991). Culture and the self: Implications for cognition, emotion, and motivation. Psychological Review, 98(2), 224. http://dx.doi.org/10.1037/0033-295X.98.2.224

Morse, J.M. (1995). The significance of saturation. Qualitative Health Research, 5(2), 147-149. http://dx.doi.org/10.1177/104973239500500201

Mussweiler, T., Gabriel, S., \& Bodenhausen, G.V. (2000). Shifting social identities asa strategy for deflecting threatening social comparisons. Journal of Personality and Social Psychology, 79(3), 398. http://dx.doi.org/10.1037/0022-3514.79.3.398

Organ, D.W. (1997). Organizational citizenship behavior: It's construct clean-uptime. Human Performance, 10(2), 85-97. http://dx.doi.org/10.1207/s15327043hup1002_2

Peng, K., \& Nisbett, R.E. (1999). Culture, dialectics, and reasoning about contradiction. American Psychologist, 54(9), 741. http://dx.doi.org/10.1037/0003-066X.54.9.741

Pettigrew, T.F. (1967). Social evaluation theory: convergences and applications. Nebraska symposium on motivation.

Podsakoff, P.M., Mackenzie, S.B., \& Bommer, W.H. (1996). Transformational leader behaviors and substitutes for leadership as determinants of employee satisfaction, commitment, trust, and organizational citizenship behaviors. Journal of Management, 22(2), 259-298. http://dx.doi.org/10.1177/014920639602200204

Podsakoff, P.M., MacKenzie, S.B., Moorman, R.H., \& Fetter, R. (1990). Transformational leader behaviors and their effects on followers' trust in leader, satisfaction, and organizational citizenship behaviors. The Leadership Quarterly, 1(2), 107-142. http://dx.doi.org/10.1016/10489843(90)90009-7

Podsakoff, P.M., MacKenzie, S.B., Podsakoff, N.P. \& Lee, J.Y. (2003). The mismeasure of man (agement) and its implications for leadership research. The Leadership Quarterly, 14(6), 615-656. http://dx.doi.org/10.1016/j.leaqua.2003.08.002 
Richins, M.L. (1991). Social comparison and the idealized images of advertising. Journal of consumer research, 18(1), 71-83. http://dx.doi.org/10.1086/209242

Rioux, S.M., \& Penner, L.A. (2001). The causes of organizational citizenship behavior: a motivational analysis. Journal of applied Psychology, 86(6), 1306. http://dx.doi.org/10.1037/00219010.86.6.1306

Ruble, D.N., \& Flett, G.L. (1988). Conflicting goals in self-evaluative information seeking: Developmental and ability level analyses. Child Development, 59(1), 97-106. http://dx.doi.org/10.2307/1130392

Ruble, D.N., \& Frey, K.S. (1991). Changing patterns of comparative behavior as skills are acquired: A functional model of self-evaluation. Hillsdale, NJ: Eribaum.

Schappe, S.P. (1998). The influence of job satisfaction, organizational commitment, and fairness perceptions on organizational citizenship behavior. The Journal of Psychology, 132(3), 277-290. http://dx.doi.org/10.1080/00223989809599167

Schwartz, J.M., \& Smith, W.P. (1976). Social comparison and the inference of ability difference. Journal of Personality and Social Psychology, 34(6), 1268. http://dx.doi.org/10.1037/00223514.34.6.1268

Sedikides, C. (1993). Assessment, enhancement, and verification determinants of the selfevaluation process. Journal of Personality and Social Psychology, 65(2), 317.

http://dx.doi.org/10.1037/0022-3514.65.2.317

Shapiro, D.L., Von Glinow, M.A., \& Xiao, Z. (2007). Toward polycontextually sensitive research methods. Management and Organization Review, 3(1), 129-152. http://dx.doi.org/10.1111/j.17408784.2007.00058.x

Shikanai, K. (1978). Effects of self-esteem on attribution of success-failure. Japanese Journal of Experimental Social Psychology, 18(1978-1979)(1), 35-46. http://dx.doi.org/10.2130/jjesp.18.35

Spector, P.E., \& Fox, S. (2010). Counterproductive work behavior and organizational citizenship behavior: Are they opposite forms of active behavior?. Applied Psychology, 59(1), 21-39. http://dx.doi.org/10.1111/j.1464-0597.2009.00414.x

Spencer-Rodgers, J., Boucher, H.C., Mori, S.C., Wang, L., \& Peng, K. (2009). The dialectical self-concept: Contradiction, change, and holism in East Asian cultures. Personality and Social Psychology Bulletin, 35(1), 29-44. http://dx.doi.org/10.1177/0146167208325772

Suls, J.M., \& Miller, R.L. (1977). Social comparison processes: Theoretical and empirical perspectives. Oxford: Hemisphere. 
Taylor, S.E., \& Lobel, M. (1989). Social comparison activity under threat: downward evaluation and upward contacts. Psychological Review, 96(4), 569. http://dx.doi.org/10.1037/0033295X.96.4.569

Tennen, H., McKee, T.E., \& Affleck, G. (2000). Social comparison processes in health and illness. In Handbook of social comparison (pp. 443-483). Springer. http://dx.doi.org/10.1007/9781-4615-4237-7_21

Tesser, A. (1988). Toward a self-evaluation maintenance model of social behavior. Advances in Experimental Social Psychology, 21, 181-227. http://dx.doi.org/10.1016/S0065-2601(08)60227-0

Ting-Toomey, S. (1988). A face negotiation theory. In Theory and intercultural communication (pp. 47-92).

Van Der Zee, A., Agterberg, C., Peeters, M., Mooi, F., \& Schellekens, J. (1996). A clinical validation of Bordetella pertussis and Bordetella parapertussis polymerase chain reaction: comparison with culture and serology using samples from patients with suspected whooping cough from a highly immunized population. Journal of Infectious Diseases, 174(1), 89-96. http://dx.doi.org/10.1093/infdis/174.1.89

Vroom, V.H. (1964). Work and motivation. New York: John Wiley \& Sons.

Wei, M., Álvarez, A.N., Ku, T.-Y., Russell, D.W., \& Bonett, D.G. (2010). Development and validation of a Coping with Discrimination Scale: factor structure, reliability, and validity. Journal of Counseling Psychology, 57(3), 328. http://dx.doi.org/10.1037/a0019969

Williams, S., Pitre, R., \& Zainuba, M. (2002). Justice and organizational citizenship behavior intentions: Fair rewards versus fair treatment. The Journal of Social Psychology, 142(1), 33-44. http://dx.doi.org/10.1080/00224540209603883

Wills, T.A. (1981). Downward comparison principles in social psychology. Psychological Bulletin, 90(2), 245. http://dx.doi.org/10.1037/0033-2909.90.2.245

Wilson, A.E., \& Ross, M. (2001). From chump to champ: people's appraisals of their earlier and present selves. Journal of Personality and Social Psychology, 80(4), 572. http://dx.doi.org/10.1037/0022-3514.80.4.572

Wong, Y.-T., Ngo, H.-Y., \& Wong, C.-S. (2006). Perceived organizational justice, trust, and OCB: A study of Chinese workers in joint ventures and state-owned enterprises. Journal of World Business, 41(4), 344-355. http://dx.doi.org/10.1016/j.jwb.2006.08.003 
Wong, Y.J., Kim, B.S., Nguyen, C.P., Cheng, J.K.Y., \& Saw, A. (2014). The interpersonal shame inventory for Asian Americans: scale development and psychometric properties. Journal of Counseling Psychology, 61(1), 119. http://dx.doi.org/10.1037/a0034681

Wood, J.V., Taylor, S.E., \& Lichtman, R.R. (1985). Social comparison in adjustment to breast cancer. Journal of Personality and Social Psychology, 49(5), 1169. http://dx.doi.org/10.1037/00223514.49.5.1169

Zell, E., \& Alicke, M.D. (2009). Self-evaluative effects of temporal and social comparison. Journal of Experimental Social Psychology, 45(1), 223-227.

http://dx.doi.org/10.1016/j.jesp.2008.09.007

Journal of Industrial Engineering and Management, 2015 (www.jiem.org)

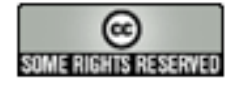

Article's contents are provided on an Attribution-Non Commercial 3.0 Creative commons license. Readers are allowed to copy, distribute and communicate article's contents, provided the author's and Journal of Industrial Engineering and Management's names are included. It must not be used for commercial purposes. To see the complete license contents, please visit http://creativecommons.org/licenses/by-nc/3.0/. 